\title{
The impact of smoking on the clinical outcome of locoregionally advanced nasopharyngeal carcinoma after chemoradiotherapy
}

\author{
Shan-Shan Guo ${ }^{1,2 \dagger}$, Pei-Yu Huang ${ }^{1,2 \dagger}$, Qiu-Yan Chen ${ }^{1,2}$, Huai Liu ${ }^{1,2}$, Lin-Quan Tang 1,2, Lu Zhang ${ }^{1,2}$, Li-Ting Liu 1,2,
} Ka-Jia Cao ${ }^{1,2}$, Ling Guo ${ }^{1,2}$, Hao-Yuan Mo ${ }^{1,2}$, Xiang Guo ${ }^{1,2}$, Ming-Huang Hong ${ }^{1,3}$ and Hai-Qiang Mai ${ }^{12^{*}}$

\begin{abstract}
Background: Cigarette smoking is a common risk factor for developing nasopharyngeal carcinoma. However, the relationship between smoking and clinical outcomes remains uncertain.

Methods: The patients who participated in this study were drawn from a randomized clinical trial, for which the purpose was to compare the efficacy of induction chemotherapy plus concurrent chemoradiotherapy with that of induction chemotherapy plus radiotherapy in patients with locoregionally advanced nasopharyngeal carcinoma. The patients who ever smoked were divided into the following categories of cumulative smoking exposure based on the duration of smoking and the quantity of cigarettes smoked: light, short-term smokers; light, long-term smokers; heavy, short-term smokers; and heavy, long-term smokers. A log-rank test and Cox models were used to assess the association between smoking and the clinical outcomes of overall survival (OS), failure-free survival (FFS), locoregional recurrence failure-free survival (LRFFS) and distant failure-free survival (DFFS).

Results: We found that ever-smokers experienced significantly shorter LRFFS times than never-smokers (5-year LRFFS rates: $85.8 \%$ vs. $88.5 \%, P=0.022)$. The amount of smoking was significantly associated with FFS $(P=0.046)$ and LRFFS $(P=0.001)$ in the different ever-smoker groups. The amount of smoking was associated with $L R F F S[P=0.002$, $\mathrm{HR}=2.069$ (95\% confident interval (Cl), 1.298-3.299)] even after a multivariable adjustment.

Conclusions: Smoking increases the risk of locoregional recurrence. Furthermore, the amount of smoking influences the prognosis of smokers, and these effects are dose-dependent.
\end{abstract}

Keywords: Nasopharyngeal carcinoma, Prognostic factor, Radiotherapy, Smoking

\section{Background}

Nasopharyngeal carcinoma (NPC) is rare in most parts of the world but is endemic in southern China and southern Asia. There were approximately 84,400 incident cases of NPC and 51,600 NPC-related deaths in 2008 throughout the world [1]. A variety of risk factors have been correlated with NPC, including alcohol, tobacco, Cantonese-style salted fish, occupational exposures and herbal drugs [2].

\footnotetext{
*Correspondence: maihq@sysucc.org.cn

${ }^{\dagger}$ Equal contributors

'Sun Yat-sen University Cancer Center, State Key Laboratory of Oncology in South China, Collaborative Innovation Center for Cancer Medicine,

Guangzhou, P. R. China

${ }^{2}$ Department of Nasopharyngeal Carcinoma, Sun Yat-sen University Cancer

Center, 651 Dongfeng Road East, Guangzhou 510060, P. R. China

Full list of author information is available at the end of the article
}

Among these, smoking has been definitively associated with the risk for the onset of NPC because former and current smokers display increased risks compared to neversmokers [3]. It was reported that 301 million smokers lived in China in 2010 [4]. To date, little information exists regarding cigarette smoking and the progression and outcome of NPC, which reveals the importance of analyzing the prognostic role of cigarette smoking among NPC patients.

We hypothesized that cigarette smoking is associated with the biological prognosis and clinical outcome for NPC. To verify our hypothesis, we used the data from a large, prospective, randomized clinical trial that compared the efficacy of induction chemotherapy plus concurrent chemoradiotherapy (IC+CCRT) with that of induction 
chemotherapy plus radiotherapy $(\mathrm{IC}+\mathrm{RT})$ in patients with locoregionally advanced nasopharyngeal carcinoma $[5,6]$.

\section{Methods}

\section{Ethics statement}

The clinical trial and this retrospective study were approved by the Research Ethics Committee of Sun Yat-sen University Cancer Center, Guangzhou, PR China. All patients had signed informed consent forms in the clinical trial, and informed consent was given by participants for their clinical records to be used in this study. Patient records were anonymized and de-identified prior to analysis.

\section{Patient selection}

The patients who participated in this study were drawn from a randomized clinical trial, for which the purpose was to compare the efficacy of induction chemotherapy plus concurrent chemoradiotherapy (IC+CCRT) with that of induction chemotherapy plus radiotherapy (IC+RT) in patients with locoregionally advanced nasopharyngeal carcinoma; the clinical trial was conducted from February 2002 to April 2005 in our institute. All these patients had been treated with a unified conventional, 2-dimensional technique in line with the treatment policy for NPC at Sun Yat-sen University Cancer Center. Every patient had been given conditional radiotherapy at 2 Gy per fraction and 5 daily fractions per week, with a total dose of 68-70Gy. In the IC+CCRT group, the patients were treated with 2 cycles of floxuridine +carboplatin $\left(\mathrm{FuDR}, 750 \mathrm{mg} / \mathrm{m}^{2}\right.$, d1-5; carboplatin, area under the curve, AUC=6). Radiotherapy had been administered to these patients one week after completing chemotherapy. Carboplatin $(\mathrm{AUC}=6)$ had been given to the patients in this group on days 7, 28 and 49 while undergoing treatment with RT. Two cycles of FuDR d1-d5+carboplatin (FuDR, $750 \mathrm{mg} / \mathrm{m}^{2}$, d1-5; carboplatin,area under the curve, $\mathrm{AUC}=6$ ) were administered to the patients in the IC+RT group. All of these patients had received RT one week after completing chemotherapy. Only 7 patients had interruption of RT. The details of the therapeutic process could be seen in the previous studies regarding the clinical trial $[5,6]$.

In the present study, the variables that were available for analysis included a history of ever smoking (ever-smokers or never-smokers), the amount of smoking presented as cigarettes per day (CPD) (never smoked, $\leq 9,10-19,20-29, \geq 30$ ), the duration of the smoking interval (never smoked, $<10,10$ $19.9,20-29.9,30-39.9, \geq 40 \mathrm{yr}$ ) and time since the cessation of smoking ( $\geq 10,5-9.9, \leq 4.9 \mathrm{yr}$ ). These criteria were chosen based on previous studies [7-13]. All of the above data regarding smoking were prospectively collected before diagnosis. At the time of diagnosis, we divided all the NPC patients through self-reporting into ever-smokers and never-smokers, which were defined as having smoked 100 cigarettes or less than 100 cigarettes in the lifetime according to Centers for Disease Control and Prevention (CDC) of America, respectively [14]. Ever-smokers included former smokers and current smokers, who were defined as having quit smoking for more than 1 year or who consistently smoked within the last year, respectively. We further categorized the patients who ever smoked into the following groups of cumulative smoking exposure based on the duration of smoking and the quantity of cigarettes smoked: light, short-term smokers ( $\leq 19$ CPD for $\leq 19.9 \mathrm{yr}$ ); light, long-term smokers ( $\leq 19$ CPD for $\geq 20 \mathrm{yr}$ ); heavy, short-term smokers $(\geq 20$ CPD for $\leq 19.9 \mathrm{yr})$; and heavy, long-term smokers $(\geq 20$ CPD for $\geq 20 \mathrm{yr}$ ). Cut-off for cumulative smoking exposure was selected based on the midpoint of the four categories of duration of smoking and quantity smoked. Cutoff values of VCA IgA and EA IgA were set at 1:80 for VCA IgA and 1:10 for EA IgA, which were based on previous studies $[15,16]$. Acute mucosal toxicity were evaluated and recorded in accord with Common Terminology Criteria for Adverse Events (CTCAE) version 2.0.

\section{Statistical analysis}

All the events were measured from the date of random assignment, and the statistical tests were performed using the SPSS17.0 software (SPSS Inc., Chicago, IL). Descriptive statistics were calculated for patient and disease characteristics according to smoking. The associations between the categorical variables were assessed using the $\varkappa^{2}$ test. The survival rates were calculated using the Kaplan-Meier method, and the differences between the groups were compared using the log-rank test. Cox regression models were used to calculate the HRs with the associated 95\% CIs for the associations between clinical outcomes and the following multiple smoking parameters: history of ever smoking (ever-smokers or never-smokers), the amount of smoking (never smoked, $\leq 9,10-19,20-29, \geq 30 \mathrm{yr}$ ), the duration of the smoking interval (never smoked, $<10,10-19.9,20-29.9$, $30-39.9, \geq 40 \mathrm{yr})$, the time since smoking cessation $(\geq 10$, $5-9.9, \leq 4.9$ ) and the cumulative smoking exposure (light, short-term smokers; light, long-term smokers; heavy, short-term smokers; heavy, long-term smokers). The Cox regression models were adjusted for the effects of age, gender, $\mathrm{T}$ stage, $\mathrm{N}$ stage and treatment arm. Two-sided $\mathrm{P}$ values less than 0.05 were considered statistically significant.

\section{Results}

\section{Baseline characteristics}

As previously described by Huang [5,6], no significant differences were observed in FFS, locoregional control or distant control between the IC+RT and IC+CCRT groups. The IC+CCRT regimen did not improve the overall survival or failure-free survival of patients with 
locoregional advanced nasopharyngeal carcinoma compared with the IC+RT regimen $[5,6]$.

In the present study, the mean age of all the patients was 43 yr (range: 18-65 yr). The characteristics of the study population according to smoking status are described in Table 1. Of the 400 patients, 207 (51.7\%) were never-smokers and 193 (48.3\%) were ever-smokers. The ever-smokers included 34 (17.6\%) former smokers and 159 (82.4\%) current smokers. The numbers of ever-smokers

Table 1 Baseline characteristics of 400 patients with locoregionally advanced nasopharyngeal carcinoma

\begin{tabular}{|c|c|c|c|}
\hline & $\begin{array}{l}\text { Ever } 193 \\
(48.3 \%)\end{array}$ & $\begin{array}{l}\text { Never } 207 \\
(51.8 \%)\end{array}$ & $P$ value \\
\hline Age(yr), median(range) & $45(18-63)$ & $41(18-65)$ & 0.969 \\
\hline Gender & & & $<0.001$ \\
\hline Female & $3(1.6)$ & $84(40.6)$ & \\
\hline Male & 190(98.4) & $123(59.4)$ & \\
\hline \multicolumn{4}{|l|}{ T stage } \\
\hline $1-2$ & $29(15.0)$ & $28(13.5)$ & 0.668 \\
\hline 3-4 & $164(85.0)$ & 179(86.5) & \\
\hline $\mathrm{N}$ stage & & & 0.541 \\
\hline $0-1$ & $92(47.7)$ & 105(50.7) & \\
\hline $2-3$ & $101(52.3)$ & 102(49.3) & \\
\hline Clinical stage & & & 0.222 \\
\hline 3 & 103(53.4) & $123(59.4)$ & \\
\hline 4 & $90(46.6)$ & $84(40.6)$ & \\
\hline Treatment arm & & & 0.617 \\
\hline IC + CCRT & $99(51.3)$ & $101(48.8)$ & \\
\hline $\mathrm{IC}+\mathrm{RT}$ & $94(48.7)$ & $106(51.2)$ & \\
\hline RT dose(Gy),median(range) & $72(68-78)$ & $72(68-78)$ & 0.773 \\
\hline CT course, median(range) & $3(1-5)$ & $3(1-5)$ & 0.079 \\
\hline RT interruption & & & 0.936 \\
\hline yes & $4(2.1)$ & $3(1.4)$ & \\
\hline no & 189(97.9) & 204(98.6) & \\
\hline AMT & & & 0.559 \\
\hline $1-2$ & 182(93.8) & 196(95.1) & \\
\hline $3-4$ & $11(6.2)$ & $10(4.9)$ & \\
\hline VCA-IgA & & & 0.833 \\
\hline Positive( $\geq 1: 80$ ) & 174(90.2) & 187(96.6) & \\
\hline Negative $(<1: 80)$ & 19(9.8) & $19(3.4)$ & \\
\hline EA-IgA & & & 0.181 \\
\hline Positive( $\geq 1: 10)$ & 151(78.2) & 172(83.6) & \\
\hline Negative $(<1: 10)$ & $42(21.8)$ & $34(16.4)$ & \\
\hline $\begin{array}{l}\text { Median follow-up yr, } \\
\text { median(range) }\end{array}$ & $6.5(0.2-9.0)$ & $6.9(0.6-9.3)$ & 0.236 \\
\hline
\end{tabular}

Abbreviations: $\mathrm{IC}+\mathrm{CCRT}=$ induction chemotherapy plus concurrent chemoradiotherapy and IC + RT = induction chemotherapy plus radiotherapy. $\mathrm{RT}=$ radiotherapy $. \mathrm{CT}=$ chemotherapy. $\mathrm{AMT}=$ Acute mucosal toxicity . in each of the cumulative smoking exposure groups were as follows: 32 (16.8\%) patients were light, short-term smokers; 18 (8.4\%) were light, long-term smokers; 57 (29.8\%) were heavy, short-term smokers; and $86(45.0 \%)$ were heavy, long-term smokers. Age, the tumor size (T1-2, T3-4), the lymph node status (N0-1, N2-3), the clinical stage, the treatment arm, RT doses, RT interruptions, CT courses, acute mucosal toxicity(1-2,3-4), VCA-IgA (Positive( $\geq 1: 80$ ), Negative $(<1: 80)$ ), EA-IgA (Positive $(\geq 1: 10)$, Negative $(<1: 10)$ ) and the median follow-up time did not differ between the neversmokers and ever-smokers, but there was a difference regarding gender $(\mathrm{P}<0.001)$ (Table 1). Age, the tumor size (T1-2, T3-4), the lymph node status (NO-1, N2-3), the clinical stage, the treatment arm, RT doses, RT interruptions, CT courses, acute mucosal toxicity(1-2,3-4), VCA-IgA (Positive $(\geq 1: 80)$, Negative $(<1: 80)$ ), EA-IgA (Positive $(\geq 1: 10)$, Negative $(<1: 10))$ and the median follow-up time were not different between the 4 cumulative smoking groups, but there was a difference regarding gender $(\mathrm{P}=0.005)$ (Table 2).

\section{Survival results according to cumulative smoking} exposure and multivariate analysis for different endpoints The median follow-up time was 80.2 mo (range $=40.9$ $92.1 \mathrm{mo}$ ). During the follow-up, 149 patients (37\%) died, 121 patients (30\%) had distant metastasis, and $62(16 \%)$ patients experienced a locoregional recurrence.

For the entire group, the actuarial 5-yr OS, FFS, LRFFS and DFFS rates were $71.5 \%, 62.6 \%, 86.2 \%$ and $71.5 \%$, respectively. OS, FFS and DFFS were not associated with smoking between the ever-smokers and never-smokers. As shown in Figure 1, the 5-yr LRFFS rates in ever-smokers and never-smokers were $85.8 \%$ and $88.5 \%(\mathrm{P}=0.022)$, respectively. After adjusting for age, gender, the $\mathrm{T}$ stage, the $\mathrm{N}$ stage, the clinical stage and the treatment arm, smoking was still related to LRFFS $[\mathrm{P}=0.002, \mathrm{HR}=2.223$ (95\% CI, 1.351-3.658)] (Table 3).

No significant difference in the OS, FFS, LRFFS or DFFS rates between the former and current smokers was evident. The 5-yr OS rates in the light, short-term smokers, the light, long-term smokers, the heavy, shortterm smokers and the heavy, long-term smokers were $62.0 \%, 77.8 \%, 74.3 \%$ and $63.0 \%$, respectively. No significant difference was found among these 4 cumulative smoking groups in OS, FFS, DFFS or LRFFS. We found that the amount of smoking was significantly associated with FFS $(\mathrm{P}=0.046)$ and LRFFS $(\mathrm{P}=0.022)$ in the eversmokers, but this factor was not associated with OS or DFFS (Figures 2 and 3). The duration of smoking was not associated with OS, FFS, DFFS or LRFFS. After adjusting for age, gender, the $\mathrm{T}$ stage, the $\mathrm{N}$ stage, the clinical stage and the treatment arm, the amount of smoking was significantly associated with LRFFS $[\mathrm{P}=0.002, \mathrm{HR}=2.233$ (95\% CI, 1.351-3.658)]. 
Table 2 Baseline characteristics of 193 ever-smokers with locoregionally advanced nasopharyngeal carcinoma

\begin{tabular}{|c|c|c|c|c|c|}
\hline & Light, short-term & Light, long-term & Heavy, short-term & Heavy, long-term & $P$ value \\
\hline & $32(16.8 \%)$ & 18(8.4\%) & $57(29.8 \%)$ & $86(45.0 \%)$ & \\
\hline Age, yr, median & $40(20-58)$ & $50(36-60)$ & $39(24-59)$ & $49(10-66)$ & 0.452 \\
\hline Gender & & & & & 0.005 \\
\hline Female & $1(3.1)$ & $1(12.5)$ & 0 & 0 & \\
\hline Male & $31(96.9)$ & $17(87.5)$ & $57(100)$ & $86(100)$ & \\
\hline T stage & & & & & 0.368 \\
\hline $1-2$ & $7(21.9)$ & $1(5.6)$ & $8(14.0)$ & $13(15.1)$ & \\
\hline $3-4$ & $25(78.1)$ & $17(94.4)$ & $49(86.0)$ & 73(84.9) & \\
\hline $\mathrm{N}$ stage & & & & & 0.463 \\
\hline $0-1$ & $16(48.5)$ & $6(33.3)$ & $25(43.9)$ & $45(52.3)$ & \\
\hline $2-3$ & $17(51.5)$ & $12(66.7)$ & $32(56.1)$ & $41(47.7)$ & \\
\hline Clinical stage & & & & & 0.189 \\
\hline 3 & $15(46.9)$ & 14(75.0) & $34(59.6)$ & $43(50.0)$ & \\
\hline 4 & $17(53.1)$ & $4(25.0)$ & $23(40.4)$ & $43(50.0)$ & \\
\hline Treatment arm & & & & & 0.641 \\
\hline IC + CCRT & $16(50.0)$ & $11(61.1)$ & $32(56.1)$ & $41(47.7)$ & \\
\hline $\mathrm{IC}+\mathrm{RT}$ & $16(50.0)$ & $7(38.9)$ & $25(43.9)$ & $45(52.3)$ & \\
\hline RT dose(Gy),median(range) & $72(68-78)$ & 72(68-78) & $72(68-78)$ & 72(68-78) & 0.118 \\
\hline CT course, median(range) & $2(2-5)$ & $32(1-5)$ & $22(1-5)$ & $22(1-5)$ & 0.470 \\
\hline \multicolumn{6}{|l|}{ RT interruption } \\
\hline Yes & $2(6.2)$ & $0(0)$ & $1(1.8)$ & $1(1.2)$ & 0.337 \\
\hline No & $30(93.8)$ & $18(100)$ & $55(98.2)$ & $85(98.8)$ & \\
\hline AMT & & & & & 0.731 \\
\hline $1-2$ & $30(93.8)$ & $18(100)$ & $52(92.9)$ & $80(93.0)$ & \\
\hline $3-4$ & $2(6.2)$ & $0(0)$ & $4(7.1)$ & $6(7.0)$ & \\
\hline VCA-IgA & & & & & 0.330 \\
\hline Positive $(\geq 1: 80)$ & $30(93.8)$ & $17(94.4)$ & $47(83.9)$ & 79(91.9) & \\
\hline Negative & $2(6.3)$ & $1(5.6)$ & $9(16.1)$ & $7(8.1)$ & \\
\hline$E A-\lg A$ & & & & & 0.121 \\
\hline Positive $(\geq 1: 10)$ & $27(84.4)$ & $17(94.4)$ & $39(69.6)$ & $67(77.9)$ & \\
\hline Negative & $5(15.6)$ & $1(5.6)$ & $17(30.4)$ & 19(22.1) & \\
\hline Median follow-up yr (range) & $6.8(0.5-8.7)$ & $6.9(1.1-8.3)$ & $6.5(0.2-8.6)$ & $6.2(0.6-9.0)$ & 0.572 \\
\hline
\end{tabular}

Abbreviations: IC + CCRT = induction chemotherapy plus concurrent chemoradiotherapy and IC + RT = induction chemotherapy plus radiotherapy. AMT = Acute mucosal toxicity.

\section{Discussion}

Tobacco use, which is responsible for approximately onethird of all cancer deaths annually, is the largest preventable cause of cancer and cancer mortality [17]. Nearly half of our study cases were current or former smokers, which emphasizes the fact that smoking is significantly associated with the risk for the onset of NPC. Jia et al. reported that individuals who reported a high cumulative amount of smoking had an increased risk of NPC compared with never-smokers [18]. A number of studies have reported that smoking is a predictor of unfavorable survival among head and neck cancer patients [17,19-22], and most of these studies have shown that smoking before treatment is associated with a worse clinical outcome. A multicenter European study demonstrated that cigarette smoking adversely affects survival, in particular, in cases of a tumor originating at the endolarynx [20]. A prospective cohort study indicated that smoking status was the strongest predictor of survival in both current smokers [hazard ratio $(\mathrm{HR})=2.4$; 95\% CI, 1.3-4.4] and former smokers $(\mathrm{HR}=2.0$; $95 \% \mathrm{CI}, 1.2-3.5)$, and the data revealed a significant association with poor survival among patients with head and 


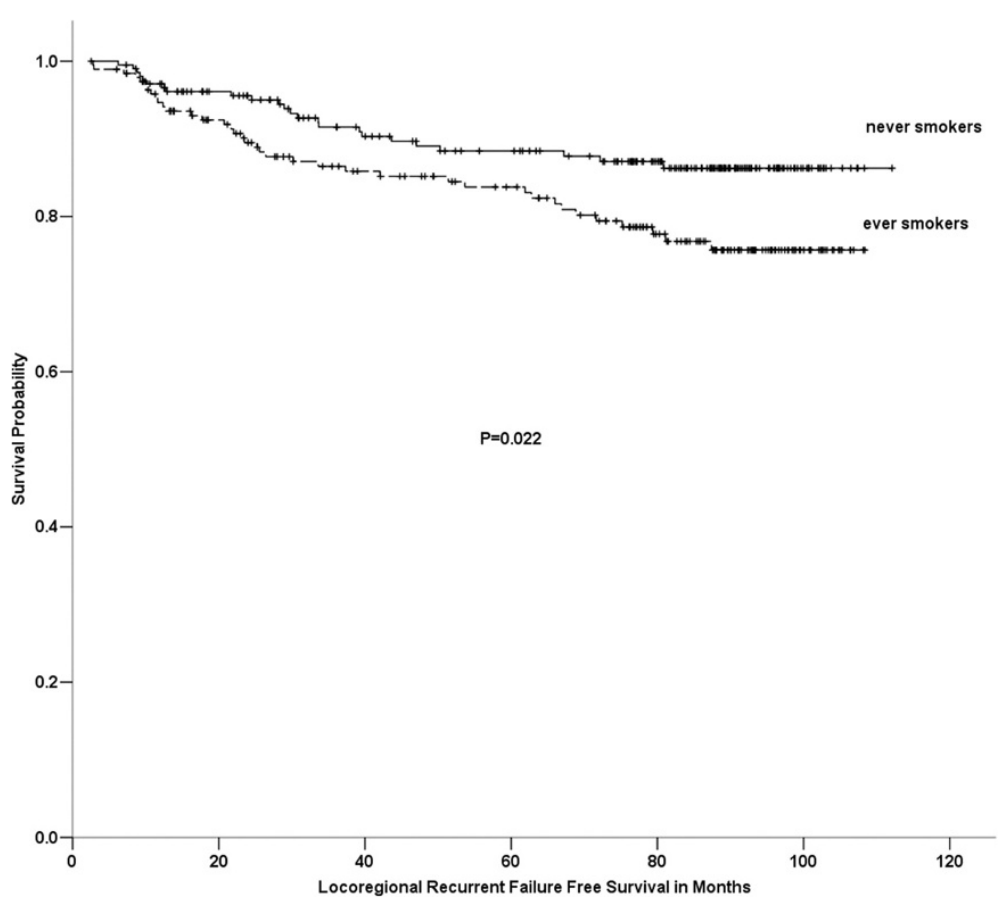

Figure 1 Comparison among ever-smokers and never-smokers on locoregional recurrence failure free survival of 400 patients with locoregionally advanced nasopharyngeal carcinoma.

neck squamous carcinoma [21]. Chen et al. has reported that, among male NPC patients, smokers have a significantly reduced 5-yr overall survival and locoregional recurrence free survival compared with non-smokers [23]. Ouyang et al. found that the risks of death, progression, locoregional relapse, and distant metastasis were significantly higher for former and current smokers than never smokers [24]. Both of the two recent researches were retrospective studies.

The present study utilized data from a randomized clinical trial that included 400 patients with locoregionally advanced carcinoma. We prospectively collected data of smoking before diagnosis, so the results of our study may be more credible than the two retrospective studies $[23,24]$. We have found that cigarette smoking is significantly associated with an increased incidence of

Table 3 Multivariable analysis of LRFFS among all patients using a Cox regression model

\begin{tabular}{llll}
\hline Characteristics & HR & $\mathbf{9 5 \% C l}$ & $\boldsymbol{P}$ value \\
\hline Age & 1.002 & $0.969-1.035$ & 0.924 \\
Gender & 0.134 & $0.016-1.149$ & 0.067 \\
T stage & 0.871 & $0.426-1.781$ & 0.705 \\
$\mathbf{N}$ stage & 0.915 & $0.569-1.473$ & 0.715 \\
Clinical stage & 1.799 & $0.705-4.589$ & 0.219 \\
Treatment arm & 1.160 & $0.605-2.224$ & 0.654 \\
Smoking amount & 2.223 & $1.351-3.658$ & 0.002 \\
\hline
\end{tabular}

Abbreviations: $\mathrm{HR}=$ hazard ratio; $\mathrm{Cl}=$ confidence interval. locoregional disease failure. However, we did not find the relevance between cigarette smoking and OS, FFS and DFFS in the present study. Because some of the patients who experienced local regional recurrence could be cured by salvage therapy. Novel treatment techniques and strategies-including precision radiotherapy, endoscopic surgery, radical neck dissections third-generation chemotherapy regimens, and targeted therapies and immunotherapy have provided hope for patients with recurrent nasopharyngeal carcinoma $[25,26]$. So smoking does not have an impact on OS. Smoking is a factor for tumor growth, and cigarette smoke acts as a mutagen and DNA damaging agent that drives tumor initiation in normal epithelial cells $[27,28]$. Cigarettes could cause genetic mutations and methylation, thereby resulting in the transformation of epithelial cells in the nasopharynx, an area in contact with potentially carcinogenic substances in cigarettes directly through inhalation [29]. So cigarette smoking has impact on local epithelial cells directly, although not having sufficient power to significantly influence disease distant metastasis.

Smoking is a factor for tumor growth, and cigarette smoke acts as a mutagen and DNA damaging agent that drives tumor initiation in normal epithelial cells [27,28]. Cigarettes could cause genetic mutations and methylation, thereby resulting in the transformation of epithelial cells in the nasopharynx, an area in contact with potentially carcinogenic substances in cigarettes directly through inhalation [29]. DNA mutations can influence local 


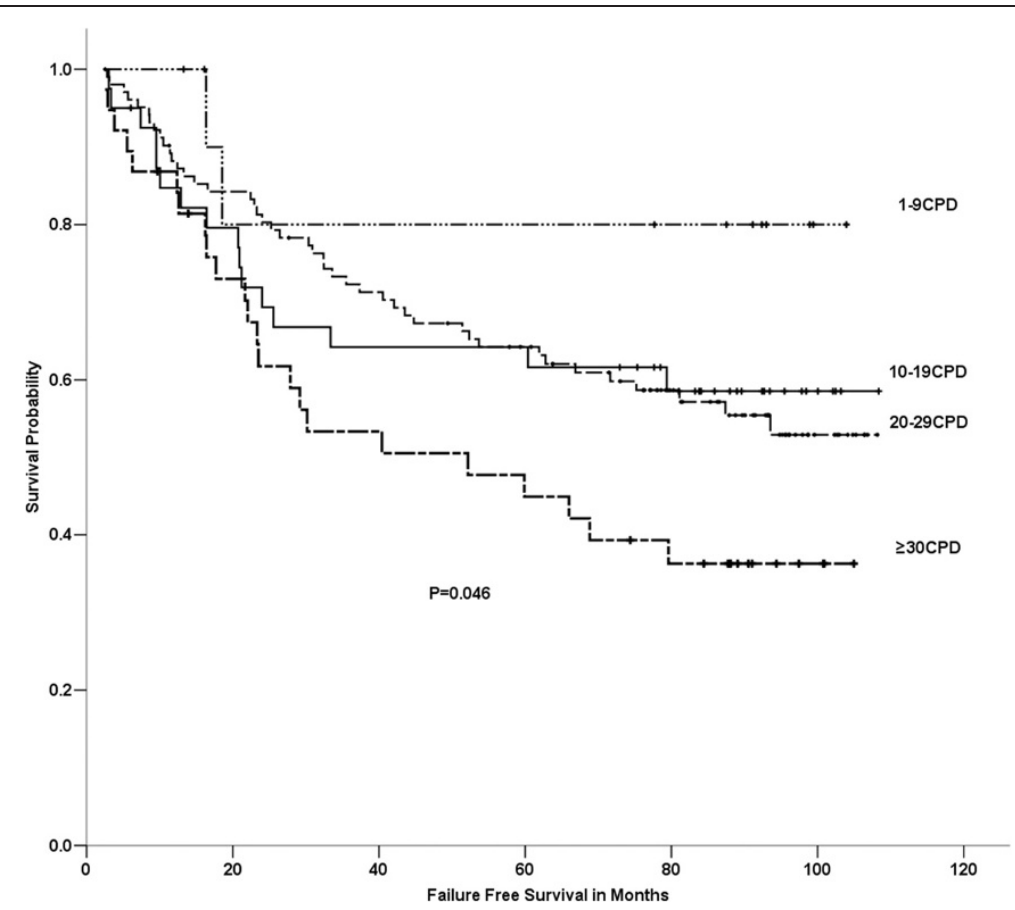

Figure 2 Comparison among different amount of smoking groups on failure free survival of 400 patients with locoregionally advanced nasopharyngeal carcinoma.

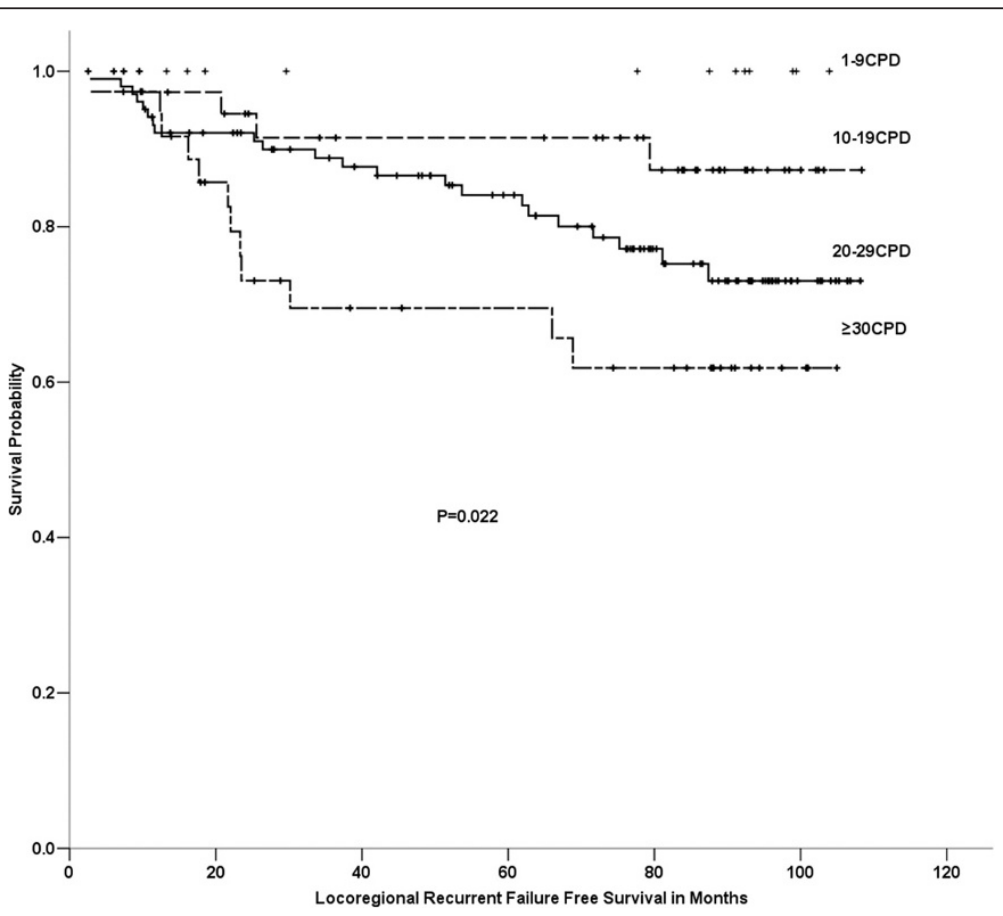

Figure 3 Comparison among different amount of smoking groups on locoregional recurrence failure free survival of 400 patients with locoregionally advanced nasopharyngeal carcinoma. 
resistance to radiation and chemotherapy [30] but should increase also distant metastasis that is frequently causes of death. However the present study showed the 5-year distant failure free survival (DFFS) in ever-smokers and never-smokers was $70.4 \%$ and $70.7 \%$, respectively $(\mathrm{P}>0.05)$. Because the effect of chemotherapy in lowering distant failure is controversial in head and neck cancer, including NPC. Adjuvant cisplatin and fluorouracil chemotherapy did not significantly improve DFFS after concurrent chemoradiotherapy in locoregionally advanced nasopharyngeal carcinoma [31,32]. Also there was no difference in DFFS between those patients treated with induction chemotherapy followed by chemoradiotherapy and those who received chemoradiotherapy alone [33,34]. Although DNA mutations have impact on resistance to chemotherapy, actually they have little impact on disease distant metastasis.

In our study, the patients who smoked more cigarettes per day were significantly associated with FFS and LRFFS. After adjusting for the $\mathrm{T}$ stage, the $\mathrm{N}$ stage, the clinical stage, age and gender, the amount of smoking was still an independent prognostic factor for LRFFS according to the Cox regression analysis. It reveals that the more cigarette smoking, the more risk of locaregional disease recurrence and disease progression in patients of nasopharyngeal carcinoma. This is in accordance with a previous study. Crosignani et al. reported that heavy tobacco smoking appeared to worsen the prognoses of male laryngeal cancer patients in a dose-dependent manner [19]. The exact explanation of this dose-dependent effect remains uncertain. It has been hypothesized that the more cigarette smoking, the more impact on the epithelial cells of nasopharynx. As a result, the risk of disease recurrent would be higher in those who smoked more cigarettes. We did not find any association between time duration of smoking and prognosis. It means that the time duration of smoking is not a prognostic factor for nasopharyngeal carcinoma. The actual mechanism about the relationship of the amount of smoking as well as time duration and prognosis would be searched by further molecular study. In the present study, former smokers did not differ from current smokers regarding LRFFS; the number of patients who had quit smoking may have been too small to reveal any differences.

In our study, acute mucosal toxicity was not different between ever-smokers and never-smokers. The relationship between acute mucosal toxicity and smoking of NPC patients remains uncertain. The result about acute mucosal toxicity is in accordance with several previous studies. Vatca et al. reported that no-smokers had a significant increase in the risk of developing severe mucositis in oropharyngeal squamous cell carcinoma $[35,36]$. Other studies yet did not find differences between smoking and mucositis in tumors including head and neck cancer [37-39]. Only one study regarding nasopharyngeal carcinoma found that smoking history are high risk factors of serious mucositis after radiotherapy for 102 NPC patients in 2005 [40]. But there were some limitations to the above study. The enrolled patients were treated with conventional radiotherapy, using cobalt 60 or $\mathrm{X}$-ray. And the sample size was too small to provide valuable evidence. The association between smoking and acute mucosal toxicity need to be explored by further largescale sample studies.

The exact mechanisms underlying the impact of smoking on cancer genesis and progression remain elusive. Recent studies showed that nicotine decreases the effectiveness of RT and chemoradiotherapy [30,41]. A previous publication revealed a relationship between smoking status and tumor oxygen unloading capacity [42]. Tobacco smoking is known to have immunosuppressive effects on local tissues via induction of pro-inflammatory cytokines and chemokines and suppression of antigen recognition and response. Cigarette smoking affects a wide range of immune functions impacting innate and adaptive host immunity, smoking induced changes in antibody production, particularly in response to foreign antigens that impinge on the respiratory mucosa [43]. Moreover, chronic exposure to cigarette smoke or nicotine causes $\mathrm{T}$ cell unresponsiveness, and nicotine-induced immunosuppression may result from its direct effects on lymphocytes [44,45]. Cigarette smokers exhibit impaired NK cytotoxic activity, increased pro-inflammatory cytokines production by peripheral mononuclear cells, and increased T-cell proliferative response to mitogens [46,47]. Smoking is a factor for tumor growth, and cigarette smoke acts as a mutagen and DNA damaging agent that drives tumor initiation in normal epithelial cells $[27,28]$. Cigarettes could cause genetic mutations and methylation, thereby resulting in the transformation of epithelial cells in the nasopharynx, an area in contact with potentially carcinogenic substances in cigarettes directly through inhalation [29]. Nicotine consistently reduced the cytotoxic effects of DNA-damaging agents used in treatment, such as cisplatin and UV and gamma radiation [30]. Besides, Epstein-Barr virus (EBV) also played a role in the progression of nasopharyngeal carcinoma. EBV reactivation in $\mathrm{B}$ cells could be triggered by cellular products of tumor cells [48]. Conversely, EBV might act as a promoter for tumorigenesis in a feedback loop. EBV reactivation is associated with the elevations of levels of cytokines and growth factors, ie, interleukin-6, interleukin10 , transforming growth factor- $\beta 1$, and vascular endothelial growth factor, which could contribute to cell proliferation, immune system perturbation, and angiogenesis [49-52].

Our study has some limitations. First and foremost, other smoking forms were not recorded, such as hookah smoking, smoking a pipe, second-hand smoke and so on. In addition, our data were collected from a single 
cancer center, and it is not known whether the conclusion from our center can be expanded to other regions. Multicenter clinical trials may be able to verify the value of pretreatment smoking cessation in locoregional advanced nasopharyngeal carcinoma patients.

\section{Conclusions}

We determined the effects of cigarette smoking on the clinical outcomes of NPC patients. Smoking leads to an increased risk of locoregional disease recurrence. Furthermore, the amount of smoking influences the prognosis of smokers, and patients who smoked more cigarettes per day have a greater risk of locoregional disease recurrence than those who smoke fewer cigarettes per day.

\section{Abbreviations}

OS: Overall survival; FFS: Failure-free survival; LRFFS: Locoregional recurrence failure-free survival; DFFS: Distant failure-free survival; Cl: Confident interval; NPC: Nasopharyngeal carcinoma; IC + CCRT: Induction chemotherapy plus concurrent chemoradiotherapy; IC + RT: Induction chemotherapy plus radiotherapy; FuDR: Floxuridine; AUC: Area under the curve; CPD: Cigarettes per day; yr: Year; CDC: Centers for disease control and prevention; CTCAE: Common terminology criteria for adverse events; RT: Radiotherapy; HR: Hazard ratio; VCA-IgA: IgA antibodies against Epstein-Barr virus capsid antigens; EA-lgA: IgA antibodies against the early antigen of Epstein-Barr virus; EBV: Epstein-Barr virus.
\end{abstract}

\section{Competing interests}

The authors declare that they have no competing interests.

\section{Authors' contributions}

Guarantors of integrity of the entire study: S-SG, P-YH, H-QM, M-HH; study concepts/study design: $\mathrm{H}-\mathrm{QM}, \mathrm{M}-\mathrm{HH}$; data analysis/interpretation: all authors; literature review: M-HH, P-YH, statistical analyses: S-SG, P-YH, manuscript drafting or revision for important intellectual content: S-SG, P-YH, H-QM; manuscript final version approval. All authors read and approved the final manuscript.

\section{Authors' information}

M.H Hong and H.Q Mai are equal leader authors.

\section{Acknowledgements}

This research was supported by grants from the National Natural Science Foundation of China (No. 81072226), the 863 Project (No. 2012AA02A501), the National Key Basic Research Program of China (No. 2013CB910304), the Sci-Tech Project Foundation of Guangdong Province (No. 2011B080701034), the Sci-Tech Project Foundation of Guangzhou City (No. 2011 J4300100), the Sun Yat-sen University Clinical Research 5010 Program and the Fundamental Research Funds for the Central Universities. The National High Technology Research and Development Program of China (863 Program No. 2012AA02A501 and 2012AA02A206). The funders had no role in study design, data collection and analysis, decision to publish, or preparation of the manuscript.

\section{Author details \\ ${ }^{1}$ Sun Yat-sen University Cancer Center, State Key Laboratory of Oncology in South China, Collaborative Innovation Center for Cancer Medicine, Guangzhou, P. R. China. ${ }^{2}$ Department of Nasopharyngeal Carcinoma, Sun Yat-sen University Cancer Center, 651 Dongfeng Road East, Guangzhou 510060, P. R. China. ${ }^{3}$ GCP Center, Sun Yat-sen University Cancer Center, Guangzhou, P. R. China.}

Received: 9 February 2014 Accepted: 31 October 2014 Published online: 26 November 2014

\section{References}

1. Jemal A, Bray F, Center MM, Ferlay J, Ward E, Forman D: Global cancer statistics. CA Cancer J Clin 2011, 61(2):69-90.
2. Yu MC, Yuan JM: Epidemiology of nasopharyngeal carcinoma. Semin Cancer Biol 2002, 12(6):421-429.

3. Fachiroh J, Sangrajrang S, Johansson M, Renard H, Gaborieau V, Chabrier A Chindavijak S, Brennan P, McKay JD: Tobacco consumption and genetic susceptibility to nasopharyngeal carcinoma (NPC) in Thailand. Cancer Causes Control 2012, 23(12):1995-2002.

4. Gu D, Kelly TN, Wu X, Chen J, Samet JM, Huang JF, Zhu M, Chen JC, Chen CS, Duan X, Klag MJ, He J: Mortality attributable to smoking in China. N Eng/J Med 2009, 360(2):150-159.

5. Huang PY, Wang CT, Cao KJ, Guo X, Guo L, Mo HY, Wen BX, Wu YS, Mai HQ Hong MH: Pretreatment body mass index as an independent prognostic factor in patients with locoregionally advanced nasopharyngeal carcinoma treated with chemoradiotherapy: findings from a randomised trial. European J Cancer (Oxford, England: 1990) 2013, 49(8):1923-1931.

6. Huang PY, Cao K, Guo X, Mo HY, Guo L, Xiang YQ, Deng MQ, Qiu F, Cao SM, Guo Y, Zhang L, Li NW, Sun R, Chen QY, Luo DH, Hua YJ, Mai HQ, Hong MH: A randomized trial of induction chemotherapy plus concurrent chemoradiotherapy versus induction chemotherapy plus radiotherapy for locoregionally advanced nasopharyngeal carcinoma. Oral Oncol 2012, 48(10):1038-1044.

7. Rink M, Furberg H, Zabor EC, Xylinas E, Babjuk M, Pycha A, Lotan Y, Karakiewicz PI, Novara G, Robinson BD, Montorsi F, Chun FK, Scherr DS, Shariat SF: Impact of smoking and smoking cessation on oncologic outcomes in primary non-muscle-invasive bladder cancer. Eur Urol 2013, 63(4):724-732.

8. Rink M, Xylinas E, Margulis V, Cha EK, Ehdaie B, Raman JD, Chun FK, Matsumoto K, Lotan Y, Furberg H, Babjuk M, Pycha A, Wood CG, Karakiewicz PI, Fisch M, Scherr DS, Shariat SF: Impact of smoking on oncologic outcomes of upper tract urothelial carcinoma after radical nephroureterectomy. Eur Urol 2013, 63(6):1082-1090.

9. Vlaanderen J, Portengen L, Schuz J, Olsson A, Pesch B, Kendzia B, Stucker I, Guida F, Bruske I, Wichmann HE, Consonni D, Landi MT, Caporaso N, Siemiatycki J, Merletti F, Mirabelli D, Richiardi L, Gustavsson P, Plato N, Jöckel KH, Ahrens W, Pohlabeln H, Tardón A, Zaridze D, Field JK, 't Mannetje A, Pearce N, McLaughlin J, Demers P, Szeszenia-Dabrowska N, et al: Effect modification of the association of cumulative exposure and cancer risk by intensity of exposure and time since exposure cessation: a flexible method applied to cigarette smoking and lung cancer in the SYNERGY Study. Am J Epidemiol 2014, 179(3):290-298.

10. Luo J, Margolis KL, Wactawski-Wende J, Horn K, Messina C, Stefanick ML, Tindle HA, Tong E, Rohan TE: Association of active and passive smoking with risk of breast cancer among postmenopausal women: a prospective cohort study. BMJ (Clinical research ed) 2011, 342:d1016.

11. Ehdaie B, Furberg H, Zabor EC, Hakimi AA, Russo P: Comprehensive assessment of the impact of cigarette smoking on survival of clear cell kidney cancer. J Urol 2014, 191(3):597-602.

12. Phipps Al, Shi Q, Newcomb PA, Nelson GD, Sargent DJ, Alberts SR, Limburg PJ: Associations between cigarette smoking status and colon cancer prognosis among participants in North Central Cancer Treatment Group Phase III Trial N0147. J Clin Oncol 2013, 31(16):2016-2023.

13. Freedman ND, Abnet CC, Leitzmann MF, Hollenbeck AR, Schatzkin A: Prospective investigation of the cigarette smoking-head and neck cancer association by sex. Cancer 2007, 110(7):1593-1601.

14. Malarcher A, Shah N, Tynan M, Maurice E, Rock V: State-specific secondhand smoke exposure and current cigarette smoking among adults - United States, 2008. MMWR Morb Mortal Wkly Rep 2009, 58(44):1232-1235.

15. Liu N, Cui RX, Sun Y, Guo R, Mao YP, Tang LL, Jiang W, Liu X, Cheng YK, He QM, Cho WC, Liu LZ, Li L, Ma J: A four-miRNA signature identified from genome-wide serum miRNA profiling predicts survival in patients with nasopharyngeal carcinoma. Int J Cancer 2014, 134(6):1359-1368.

16. Tang LQ, Chen QY, Guo SS, Chen WH, Li CF, Zhang L, Lai XP, He Y, Xu YX, Hu DP, Wen SH, Peng YT, Liu H, Liu LT, Yan SM, Guo L, Zhao C, Cao K, Liu Q, Qian CN, Ma J, Guo X, Zeng MS, Mai H: The impact of plasma epstein-barr virus DNA and fibrinogen on nasopharyngeal carcinoma prognosis: an observational study. Br J Cancer 2014, 111(6):1102-1111.

17. Boffetta P, Merletti F, Faggiano F, Migliaretti G, Ferro G, Zanetti R, Terracini B: Prognostic factors and survival of laryngeal cancer patients from Turin, Italy. A population-based study. Am J Epidemiol 1997, 145(12):1100-1105.

18. Xue WQ, Qin HD, Ruan HL, Shugart YY, Jia WH: Quantitative association of tobacco smoking with the risk of nasopharyngeal carcinoma: a 
comprehensive meta-analysis of studies conducted between 1979 and 2011. Am J Epidemiol 2013, 178(3):325-338.

19. Crosignani P, Russo A, Tagliabue G, Berrino F: Tobacco and diet as determinants of survival in male laryngeal cancer patients. Int J Cancer 1996, 65(3):308-313.

20. Dikshit RP, Boffetta P, Bouchardy C, Merletti F, Crosignani P, Cuchi T, Ardanaz E, Brennan P: Lifestyle habits as prognostic factors in survival of laryngeal and hypopharyngeal cancer: a multicentric European study. Int J Cancer 2005, 117(6):992-995.

21. Duffy SA, Ronis DL, McLean S, Fowler KE, Gruber SB, Wolf GT, Terrell JE: Pretreatment health behaviors predict survival among patients with head and neck squamous cell carcinoma. J Clin Oncol 2009, 27(12):1969-1975.

22. Warren GW, Kasza KA, Reid ME, Cummings KM, Marshall JR: Smoking at diagnosis and survival in cancer patients. Int J Cancer 2013, 132(2):401-410.

23. Chen C, Shen LJ, Li BF, Gao J, Xia YF: Smoking is a poor prognostic factor for male nasopharyngeal carcinoma treated with radiotherapy. Radiother Oncol 2014, 110(3):409-415.

24. Ouyang PY, Su Z, Mao YP, Liang XX, Liu Q, Deng W, Xie FY: Prognostic impact of cigarette smoking on the survival of patients with established nasopharyngeal carcinoma. Cancer Epidemiol Biomarkers Prev 2013, 22(12):2285-2294.

25. Chen C, Fee W, Chen J, Chan C, Khong B, Hara W, Goffinet D, Li D, Le QT: Salvage treatment for locally recurrent nasopharyngeal carcinoma (NPC). Am J Clin Oncol 2014, 37(4):327-331.

26. Lee AW, Fee WE Jr, Ng WT, Chan LK: Nasopharyngeal carcinoma: salvage of local recurrence. Oral Oncol 2012,48(9):768-774.

27. Furmanski P: Revealing the mechanism of tissue damage due to tobacco use: finally, a smoking gun? Am J Pathol 2013, 182(5):1489-1493.

28. Salem AF, Al-Zoubi MS, Whitaker-Menezes D, Martinez-Outschoorn UE, Lamb R, Hulit J, Howell A, Gandara R, Sartini M, Galbiati F, Bevilacqua G, Sotgia F, Lisanti MP: Cigarette smoke metabolically promotes cancer, via autophagy and premature aging in the host stromal microenvironment Cell Cycle (Georgetown, Tex) 2013, 12(5):818-825.

29. Ji X, Zhang W, Xie C, Wang B, Zhang G, Zhou F: Nasopharyngeal carcinoma risk by histologic type in central China: impact of smoking, alcohol and family history. Int J Cancer 2011, 129(3):724-732.

30. Onoda N, Nehmi A, Weiner D, Mujumdar S, Christen R, Los G: Nicotine affects the signaling of the death pathway, reducing the response of head and neck cancer cell lines to DNA damaging agents. Head Neck 2001, 23(10):860-870.

31. Chen $L$, Hu CS, Chen XZ, Hu GQ, Cheng ZB, Sun Y, Li WX, Chen YY, Xie FY, Liang SB, Chen Y, XU TT, Li B, Long GX, Wang SY, Zheng BM, Guo Y, Sun Y, Mao YP, Tang LL, Chen YM, Liu MZ, Ma J: Concurrent chemoradiotherapy plus adjuvant chemotherapy versus concurrent chemoradiotherapy alone in patients with locoregionally advanced nasopharyngeal carcinoma: a phase 3 multicentre randomised controlled trial. Lancet Oncol 2012, 13(2):163-171

32. Lee AW, Tung SY, Chua DT, Ngan RK, Chappell R, Tung R, Siu L, Ng WT, Sze WK, Au GK, Law SC, O'Sullivan B, Yau TK, Leung TW, Au JS, Sze WM, Choi CW, Fung KK, Lau JT, Lau WH: Randomized trial of radiotherapy plus concurrent-adjuvant chemotherapy vs radiotherapy alone for regionally advanced nasopharyngeal carcinoma. J Natl Cancer Inst 2010, 102(15):1188-1198.

33. Haddad R, O'Neill A, Rabinowits G, Tishler R, Khuri F, Adkins D, Clark J, Sarlis N, Lorch J, Beitler JJ, Limaye S, Riley S, Posner M: Induction chemotherapy followed by concurrent chemoradiotherapy (sequential chemoradiotherapy) versus concurrent chemoradiotherapy alone in locally advanced head and neck cancer (PARADIGM): a randomised phase 3 trial. Lancet Oncol 2013, 14(3):257-264.

34. Cohen EE, Karrison TG, Kocherginsky M, Mueller J, Egan R, Huang CH, Brockstein BE, Agulnik MB, Mittal BB, Yunus F, Samant S, Raez LE, Mehra R, Kumar P, Ondrey F, Marchand P, Braegas B, Seiwert TY, Villaflor VM, Haraf DJ, Vokes EE: Phase III randomized trial of induction chemotherapy in patients with N2 or N3 locally advanced head and neck cancer. J Clin Oncol 2014, 32(25):2735-2743.

35. Rugg T, Saunders MI, Dische S: Smoking and mucosal reactions to radiotherapy. Br J Radiol 1990, 63(751):554-556.

36. Vatca M, Lucas JT Jr, Laudadio J, D'Agostino RB, Waltonen JD, Sullivan CA, Rouchard-Plasser R, Matsangou M, Browne JD, Greven KM, Porosnicu M: Retrospective analysis of the impact of HPV status and smoking on mucositis in patients with oropharyngeal squamous cell carcinoma treated with concurrent chemotherapy and radiotherapy. Oral Oncol 2014, 50(9):869-876.
37. Dodd MJ, Miaskowski C, Shiba GH, Dibble SL, Greenspan D, MacPhail L, Paul SM, Larson P: Risk factors for chemotherapy-induced oral mucositis: dental appliances, oral hygiene, previous oral lesions, and history of smoking. Cancer Invest 1999, 17(4):278-284.

38. Wuketich S, Hienz SA, Marosi C: Prevalence of clinically relevant oral mucositis in outpatients receiving myelosuppressive chemotherapy for solid tumors. Support Care Cancer 2012, 20(1):175-183.

39. Robien K, Schubert MM, Bruemmer B, Lloid ME, Potter JD, Ulrich CM: Predictors of oral mucositis in patients receiving hematopoietic cell transplants for chronic myelogenous leukemia. J Clin Oncol 2004, 22(7):1268-1275.

40. Luo DH, Hong MH, Guo L, Cao KJ, Deng MQ, Mo HY: Analysis of oral mucositis risk factors during radiotherapy for nasopharyngeal carcinoma patients and establishment of a discriminant model. Ai Zheng 2005, 24(7):850-854.

41. Warren GW, Romano MA, Kudrimoti MR, Randall ME, McGarry RC, Singh AK, Rangnekar VM: Nicotinic modulation of therapeutic response in vitro and in vivo. Int J Cancer 2012, 131(11):2519-2527.

42. Overgaard J, Nielsen JE, Grau C: Effect of carboxyhemoglobin on tumor oxygen unloading capacity in patients with squamous cell carcinoma of the head and neck. Int J Radiat Oncol Biol Phys 1992, 22(3):407-410.

43. Holt PG: Immune and inflammatory function in cigarette smokers. Thorax 1987, 42(4):241-249.

44. Semlali A, Witoled C, Alanazi M, Rouabhia M: Whole cigarette smoke increased the expression of TLRs, HBDs, and proinflammory cytokines by human gingival epithelial cells through different signaling pathways. PLoS One 2012, 7(12):e52614.

45. Sopori ML, Kozak W: Immunomodulatory effects of cigarette smoke. J Neuroimmunol 1998, 83(1-2):148-156.

46. Zeidel A, Beilin B, Yardeni I, Mayburd E, Smirnov G, Bessler H: Immune response in asymptomatic smokers. Acta Anaesthesio/ Scand 2002, 46(8):959-964.

47. Tollerud DJ, Clark JW, Brown LM, Neuland CY, Mann DL, Pankiw-Trost LK, Blattner WA, Hoover RN: The effects of cigarette smoking on T cell subsets. A population-based survey of healthy caucasians. Am Rev Respir Dis 1989, 139(6):1446-1451.

48. Mochanko K, Fejes M, Breazavscek DM, Suarez A, Bachmann AE: The relation between Epstein-Barr virus antibodies and clinical symptomatology and immunodeficiency in patients with Hodgkin's disease. Cancer 1979, 44(6):2065-2070

49. Tan EL, Selvaratnam G, Kananathan R, Sam CK: Quantification of Epstein-Barr virus DNA load, interleukin-6, interleukin-10, transforming growth factor-beta1 and stem cell factor in plasma of patients with nasopharyngeal carcinoma. BMC Cancer 2006, 6:227.

50. Xu J, Menezes J, Prasad U, Ahmad A: Elevated serum levels of transforming growth factor beta1 in Epstein-Barr virus-associated nasopharyngeal carcinoma patients. Int J Cancer 1999, 84(4):396-399.

51. Hong GK, Gulley ML, Feng WH, Delecluse HJ, Holley-Guthrie E, Kenney SC: Epstein-Barr virus lytic infection contributes to lymphoproliferative disease in a SCID mouse model. J Virol 2005, 79(22):13993-14003.

52. Xu FH, Xiong D, Xu YF, Cao SM, Xue WQ, Qin HD, Liu WS, Cao JY, Zhang Y, Feng QS, Chen LZ, Li MZ, Liu ZW, Liu Q, Hong MH, Shugart YY, Zeng YX, Zeng MS, Jia WH: An epidemiological and molecular study of the relationship between smoking, risk of nasopharyngeal carcinoma, and Epstein-Barr virus activation. J Natl Cancer Inst 2012, 104(18):1396-1410.

\section{doi:10.1186/s13014-014-0246-y}

Cite this article as: Guo et al:: The impact of smoking on the clinical outcome of locoregionally advanced nasopharyngeal carcinoma after chemoradiotherapy. Radiation Oncology 2014 9:246. 